\title{
Experimental Study on Shape Dependent Wave Force of Offshore Support Structures
}

\author{
Youn-Ju Jeong, Min-Su Park, and Young-Jun You
}

\begin{abstract}
In this study, wave force tests were carried out for the four types of offshore support structures and wave forces to the support structure shapes were investigated. As the results of this study, it was found that, as the wave period increased at the normal state, wave force decreased for the most cases. Extreme wave force influenced by impact wave force. Impact wave force of this study significantly effect on Monopile and minutely on Hybrid type. So as to, Hybrid type indicated even lower wave force at the extreme state than the Monopile, although Hybrid type indicated higher wave force at the normal state. In respects of the structural design, since critical loading is extreme wave force, it should be contributed to improve structural safety of offshore support structure. However, since the impact wave force was dependent on the support structure shape, wave height, and wave period, more research is needed to access the impact wave force for other shapes and wave conditions.
\end{abstract}

Index Terms-Support structure, shape, test, wave force, impact.

\section{INTRODUCTION}

Offshore support structures should have a structural safety against to the harsh offshore conditions of wind, wave, and tidal. In order to improve structural safety of offshore support structure, it is important to reduce wave force and waveinduced bending moment to the support structure [1], [2]. Recently, support structures become to be large-sized. However, since the increasing of the size of support structure to improve strength and stiffness disadvantages to the wave forces subjected to the support structures because of the larger cross-sectional area, it needs to optimally arrange structural components of support structure so as to satisfy both low-wave force and high-structural safety [3].

Also, in the hydrodynamic analysis and structural analysis, wave forces subjected to the support structure were calculated from Morison equation or diffraction theory according to the shape or dimension of support structures. However, it has known that these theoretical wave forces did not reflect wave run-up or impact wave force effect at the extreme wave condition [4]-[6].

In this study, in order to investigate wave force to the shape of support structures, wave force tests were carried out for the four types of offshore support structures, Monopile [7], GBS (Gravity Base System) [7], [8], Hybrid (1), and Hybrid (2)

Manuscript received February 14, 2016; revised April 4, 2016. This work was supported in part by the South Korea Government, Ministry of Trade, Industry, and Energy, and Ministry of Oceans and Fisheries.

Youn-Ju Jeong, Min-Su Park, and Young-Jun You are with the Korea Institute of Civil Engineering and Building Technology, Goyang, Gyeonggi, South Korea, 10223 (e-mail: yjjeong@kict.re.kr, mspark@kict.re.kr, yjyou@kict.re.kr). types [3], [9], [10]. Based on the wave force tests, wave forces to the shape of the support structures were analyzed and compared with each other.

\section{WAVE FORCE TESTS}

\section{A. Test Models}

In order to evaluate wave force subjected to the offshore support structures, four types of support structures of Monopile, GBS, Hybrid (1), and Hybrid (2) were fabricated and tested under the various wave conditions, as shown in Fig. 1. Four types of support structures were designed and fabricated to have the same total weight and height applying Froude scale law of 1:25.

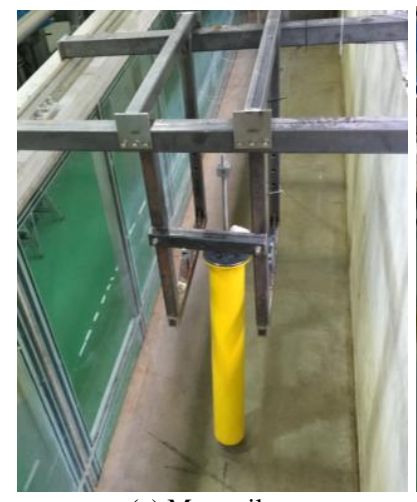

(a) Monopile

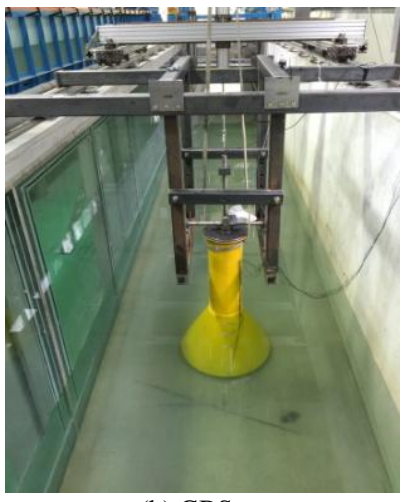

(b) GBS

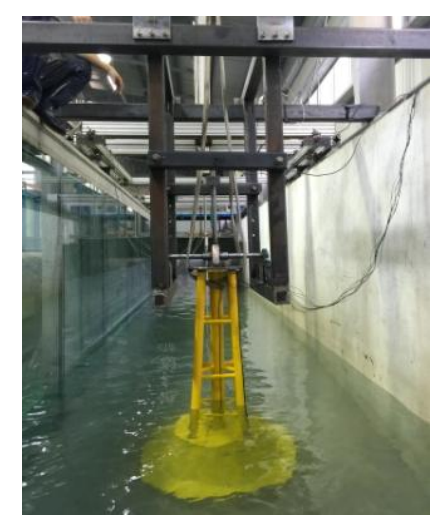

(b) Hybrid (1) and Hybrid (2) Fig. 1. Test models.

Hybrid (1) and Hybrid (2) have the same dimension but different weight of the bottom base part. Hybrid (1) and Hybrid (2) types were fabricated connecting multipiles of the upper part with the base of the bottom part. Therefore, Hybrid (1) and Hybrid (2) types have the same upper multipiles and different bottom base model in weight. The details of four support models were summarized in Table I. 
TABLE I: THE DETAILS OF TEST MODELS

\begin{tabular}{ccccccc}
\hline \hline No. & Type & Dimension $(\mathrm{mm})$ & Weight $(\mathrm{kg})$ & Wave Area $\left(\mathrm{cm}^{2}\right)$ & Wave Volume $\left(\mathrm{cm}^{3}\right)$ & Scale \\
\hline 1 & Mono & $\left.240\left(\mathrm{D}_{1}\right) \times 240 \mathrm{D}_{2}\right) \times 1,500(\mathrm{H})$ & 203.00 & $1,920.0(1.0)$ & $11,520.0(1.0)$ & $1: 25$ \\
\hline 2 & GBS & $260\left(\mathrm{D}_{1}\right) \times 740\left(\mathrm{D}_{2}\right) \times 1,500(\mathrm{H})$ & 203.00 & $4,000.0(2.1)$ & $50,000.0(4.3)$ & $1: 25$ \\
\hline 3 & Hybrid $(1)$ & $272\left(\mathrm{D}_{1}\right) \times 740\left(\mathrm{D}_{2}\right) \times 1,500(\mathrm{H})$ & 203.00 & $3,462.4(1.8)$ & $38,863.1(3.4)$ & $1: 25$ \\
\cline { 1 - 2 } \cline { 5 - 7 } 4 & Hybrid $(2)$ & $* * * \mathrm{D}_{1}=(4 \cdot \varnothing 48+\varnothing 80)^{* * * *}$ & 248.29 & $3,462.4(1.8)$ & $38,863.1(3.4)$ & $1: 25$ \\
\hline \hline
\end{tabular}

*** $\mathrm{D}_{1}$ : top diameter, $\mathrm{D}_{2}$ : bottom diameter, $\mathrm{H}$ : height

\section{B. Test Setup}

In order to investigate wave force subjected to the support structures, experimental studies were conducted at the flume of the CheonNam National University (local campus at Yeusu) of the South Korea in July, 2015. The dimensions of the flume are $100 \mathrm{~m}(\mathrm{~L}) \times 2.0 \mathrm{~m}(\mathrm{~W}) \times 3.0 \mathrm{~m}(\mathrm{H})$. The mechanical frame was specially designed and fabricated to allow wave-induced swing motion of test models with the minimum friction. Then, some device, which connected with the load-cell, to fix wave-induced swing motions of test models was attached to the mechanical frame and wave forces were measured using the load-cell, as shown in Fig. 2. In order to measure wave pressure distribution along to the water depth, five to eight hydraulic pressure gauges were attached to the front side of the test models, as shown in Fig. 2 .

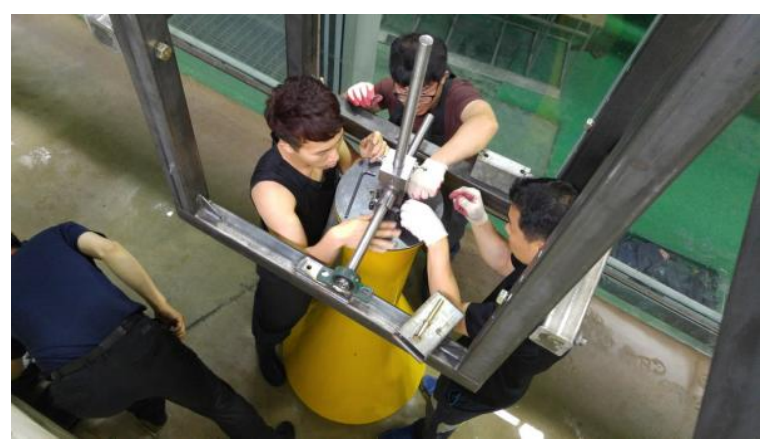

(a) Installation of constraint device and load-cell.

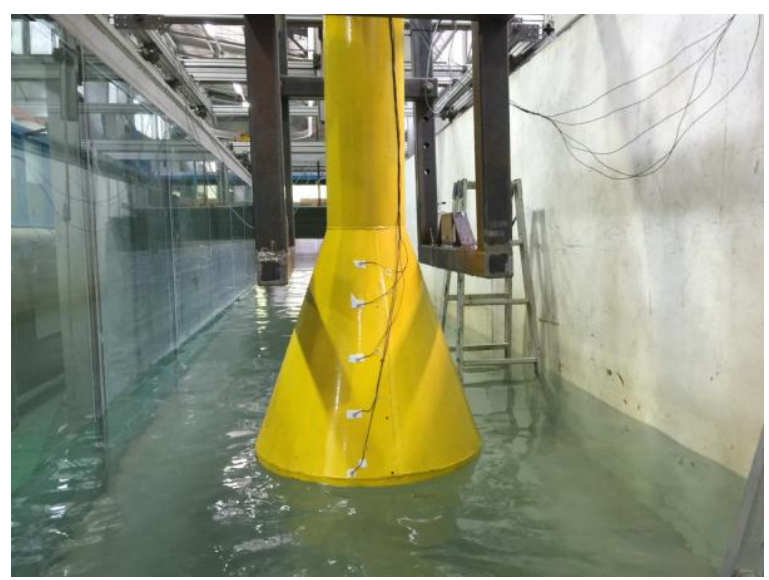

(b) Installation of hydraulic pressure gauges.

Fig. 2. Test setup.

\section{Wave Conditions}

Support structure models were tested under the six different regular wave conditions, as presented in Table II and Fig. 3. The wave variables of this wave tests were the wave height and wave period. For the full-scale models, two cases of wave height $\left(\mathrm{H}_{\mathrm{W}}\right) 3.435 \mathrm{~m}$ and $12.78 \mathrm{~m}$ were selected and these were scale downed to $0.137 \mathrm{~m}$ and $0.511 \mathrm{~m}$ for the small-scale model. Also, for the wave height $3.435 \mathrm{~m}$, five cases of wave period $\left(\mathrm{P}_{\mathrm{W}}\right) 7.5 \mathrm{~s}, 9.5 \mathrm{~s} .11 .5 \mathrm{~s}, 13.5 \mathrm{~s}$, and $15.5 \mathrm{~s}$ were selected and these were scale downed to $1.5 \mathrm{~s}, 1.9$ s, $2.3 \mathrm{~s}, 2.74 \mathrm{~s}$, and $3.1 \mathrm{~s}$ for the small-scale model. Where, wave \#3 (wave height $3.435 \mathrm{~m}$ and wave period $11.5 \mathrm{~s}$ ) was corresponded to the normal offshore condition and wave \#6 (wave height $12.78 \mathrm{~m}$ and wave period $13.7 \mathrm{~s}$ ) was corresponded to the extreme offshore condition. Water depth was $20.0 \mathrm{~m}$ and scale downed to $0.8 \mathrm{~m}$.

TABLE II: WAVE CONDITIONS

\begin{tabular}{ccccc}
\hline \hline No. & $\begin{array}{c}\text { Wave Height } \\
\mathrm{H}_{\mathrm{D}}(\mathrm{m})\end{array}$ & $\begin{array}{c}\text { Wave Period } \\
\mathrm{T}_{\mathrm{D}}(\mathrm{s})\end{array}$ & $\begin{array}{c}\text { Wave Length } \\
\mathrm{L}_{\mathrm{D}}(\mathrm{m})\end{array}$ & $\mathrm{H}_{\mathrm{D}} / \mathrm{L}_{\mathrm{D}}$ \\
\hline$\# 1$ & $0.137(3.435)$ & $1.500(7.5)$ & $3.217(80.429)$ & $1 / 23.41$ \\
\hline$\# 2$ & $0.137(3.435)$ & $1.900(9.5)$ & $4.530(113.269)$ & $1 / 32.97$ \\
\hline$\# 3$ & $0.137(3.435)$ & $2.300(11.5)$ & $5.787(144.674)$ & $1 / 42.11$ \\
\hline$\# 4$ & $0.137(3.435)$ & $2.740(13.5)$ & $7.124(178.122)$ & $1 / 51.85$ \\
\hline$\# 5$ & $0.137(3.435)$ & $3.100(15.5)$ & $8.197(204.940)$ & $1 / 59.66$ \\
\hline$\# 6$ & $0.511(12.78)$ & $2.740(13.5)$ & $7.124(178.122)$ & $1 / 13.94$ \\
\hline \hline
\end{tabular}

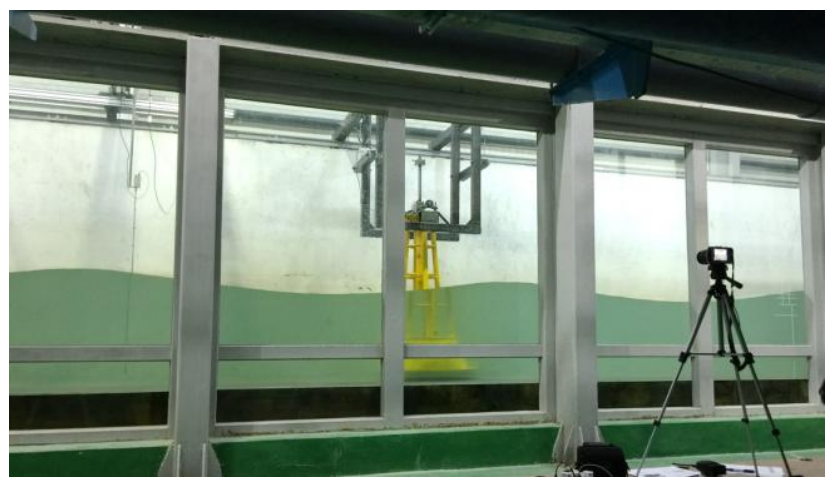

(a) Normal wave condition.

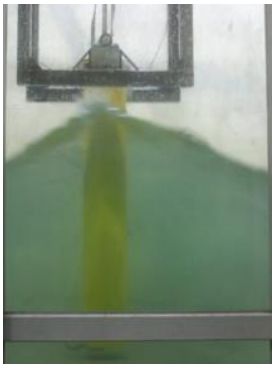

(b) Extreme wave condition: Monopile, GBS, Hybrid (1) \& (2). Fig. 3. Wave force tests.
In cases of Hybrid (1) and Hybrid (2) models, incident wave $45^{\circ}$ as well as $0^{\circ}$ was added to verify maximum wave forces according to the incident wave effect. Since the upper part of Hybrid (1) and Hybrid (2) models consist of the multiplies and indicate different wave force to the wave direction, in order to act incident wave $45^{\circ}$ effects, Hybrid (1) and Hybrid (2) models were repositioned to the $45^{\circ}$ direction 
for the wave direction.

Wave force tests were carried out during the 300 s. Among the measured time series load-cell data set, $50 \mathrm{~s}$ data sets from $200 \mathrm{~s}$ to $250 \mathrm{~s}$ was selected as the typical wave force, which was well present wave force of test models.

\section{WAVE FORCES}

As the results of wave force tests, measured wave forces for the small-scale models were presented in Fig. 4 to Fig. 7 for the support structure types, respectively. Noise of measured data set was eliminated using moving average data processing method. Based on the measured data, minimum and maximum magnitudes of the wave forces were calculated and converted for the real-scale models according to the Froude scale law.

Amplitudes of wave forces for the real-scale models were summarized in Table III. Test results of this study indicated a similar tendency with wave force theory. In case of the larger diameter support structures of GBS, wave force is calculated from diffraction theory in general, which is governed by the volume of the wave body. The wave body volume of the GBS type of this study was about $430 \%$ of the Monopile, as presented in Table I, and total wave force of GBS type ranged from $374 \%$ to $506 \%$ (average $440 \%$ ) of the Monopile at the normal wave condition of wave \#1 to wave \#5, where total wave force did not effected by wave run-up and impact wave force. In case of the slender support structures of Jacket or Multipiles, wave force is calculated from Morison equation in general, which is governed by the area of the wave body. The wave body areas of the Hybrid (1) and Hybrid (2) of this study were about $180 \%$ of the Monopile, as presented in Table I, and total wave force of Hybrid (1) and Hybrid (2) ranged from $145 \%$ to $203 \%$ (average $174 \%$ ) of the Monopile at the normal wave condition of wave \#1 to wave \#5.

At the normal wave condition of wave \#1 to wave \#5, measured wave force had a similar tendency that, as the wave period increased from wave \#1 (7.5 s) to wave \#5 (15.5 s) maintaining the same wave height of $3.435 \mathrm{~m}$, wave forces subjected to the support structure decreased for the most support structures, as presented in Fig. 8. In cases of the
Monopile and GBS, wave forces at the long wave period of $15.5 \mathrm{~s}$ were about $48.0 \%$ and $55.0 \%$ level, respectively, of the short wave period of $7.5 \mathrm{~s}$. In cases of the Hybrid (1) and Hybrid (2), wave forces at the long wave period of $15.5 \mathrm{~s}$ were about $61.0 \%$ and $56.0 \%$ level, respectively, of the short wave period of $7.5 \mathrm{~s}$. Hybrid (1) and Hybrid (2), which have the same dimension but different total weight, had the similar wave force level at the normal wave condition of wave \#1 to wave \#5. Therefore, it was found that total weight of the support structure insignificantly influence on the wave force subjected to the support structures at the normal wave condition.

At the extreme wave condition of wave \#6, measured wave force had a different tendency that, as the wave height increased from wave \#4 $(3.435 \mathrm{~m})$ to wave \#6 (12.78 m) maintaining the same wave period of $13.5 \mathrm{~s}$, wave forces subjected to the support structures drastically increased for the Monopile, and slightly increased for the GBS, Hybrid (1), and Hybrid (2) types, as presented in Fig. 9. In cases of the Monopile and GBS, wave forces at the extreme wave height of $12.78 \mathrm{~m}$ were about $1,750 \%$ and $587 \%$ level, respectively, of the normal wave height of $3.435 \mathrm{~m}$. In cases of the Hybrid (1) and Hybrid (2), wave forces at the extreme wave height of $12.78 \mathrm{~m}$ were about $423 \%$ to $435 \%$ and $636 \%$ to $686 \%$ level, respectively, of the normal wave height of $3.435 \mathrm{~m}$.

What the extreme wave force of Monopile increased drastically was caused by impact wave force called slamming force at the extreme wave condition. It has known that the wave run-up and impact wave force was mainly dependent on the shape of support structure, wave height, and wave period [4], [5]. As considering wave height ratio (373\%) of wave \#6 to wave \#4 and slamming force factors (4.3 to 5.15) for the cylinder Monopile, as indicated in Table IV, impact wave force affects largely on the total wave force of the Monopile. Also, wave-induced little vibration of test modes were observed at the extreme wave condition of wave \#6, Therefore, inertia force due to the little vibration of the test models maybe made affect the wave force at the extreme wave condition.

TABLE III: SUMMARY OF MAX. WAVE FoRCES FOR THE REAL-SCALE MODELS

\begin{tabular}{|c|c|c|c|c|c|c|c|c|}
\hline \multirow{2}{*}{ Sea State } & \multirow{2}{*}{\multicolumn{2}{|c|}{ Wave }} & \multirow{2}{*}{ Monopile } & \multirow{2}{*}{ GBS } & \multicolumn{2}{|c|}{ Hybrid (1) } & \multicolumn{2}{|c|}{ Hybrid (2) } \\
\hline & & & & & $0^{\circ}$ & $45^{\circ}$ & $0^{\circ}$ & $45^{\circ}$ \\
\hline \multirow{10}{*}{ Normal } & \multirow{2}{*}{$\# 1$} & Max. & 1,064 & 3,978 & 1,573 & 1,539 & 1,604 & 1,633 \\
\hline & & Ratio & $(100 \%)$ & $(374 \%)$ & $(148 \%)$ & $(145 \%)$ & $(151 \%)$ & $(153 \%)$ \\
\hline & \multirow{2}{*}{$\# 2$} & Max. & 793 & 3,637 & 1,487 & 1,446 & 1,398 & 1,408 \\
\hline & & Ratio & $(100 \%)$ & $(459 \%)$ & $(188 \%)$ & $(182 \%)$ & $(176 \%)$ & $(178 \%)$ \\
\hline & \multirow{2}{*}{$\# 3$} & Max. & 759 & 3,838 & 1,264 & 1,266 & 1,280 & 1,295 \\
\hline & & Ratio & $(100 \%)$ & $(506 \%)$ & $(167 \%)$ & $(167 \%)$ & $(169 \%)$ & $(171 \%)$ \\
\hline & \multirow{2}{*}{$\# 4$} & Max. & 605 & 2,636 & 1,100 & 1,093 & 1,227 & 1,230 \\
\hline & & Ratio & $(100 \%)$ & $(436 \%)$ & $(182 \%)$ & $(181 \%)$ & $(203 \%)$ & $(203 \%)$ \\
\hline & \multirow{2}{*}{$\# 5$} & Max. & 511 & 2,186 & 954 & 937 & 910 & 908 \\
\hline & & Ratio & $(100 \%)$ & $(428 \%)$ & $(187 \%)$ & $(183 \%)$ & $(178 \%)$ & $(178 \%)$ \\
\hline \multirow{2}{*}{ Extreme } & \multirow{2}{*}{$\# 6$} & Max. & 10,590 & 15,481 & 4,786 & 4,623 & 7,802 & 8,441 \\
\hline & & Ratio & $(100 \%)$ & $(146 \%)$ & $(45 \%)$ & $(44 \%)$ & $(74 \%)$ & $(80 \%)$ \\
\hline
\end{tabular}




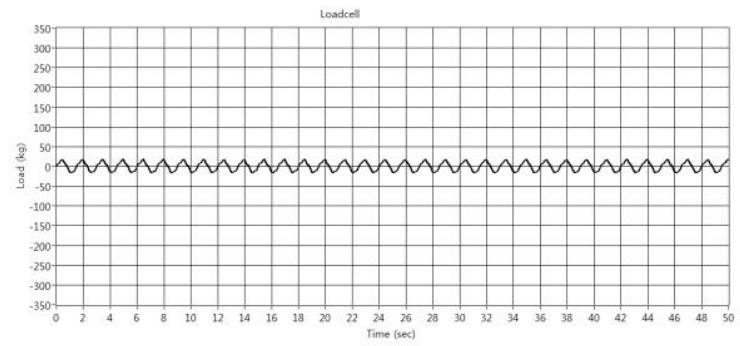

(a) Wave \#1.

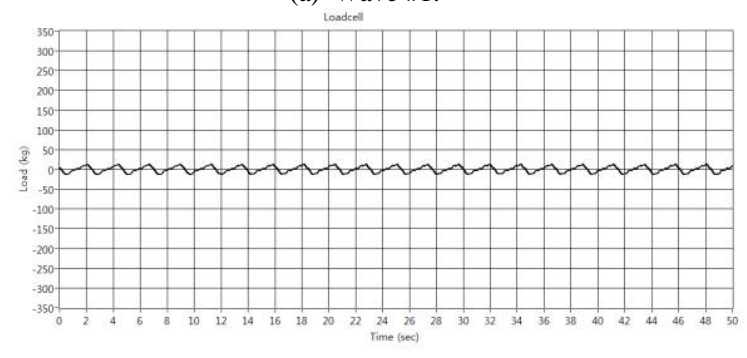

(b) Wave \#3.

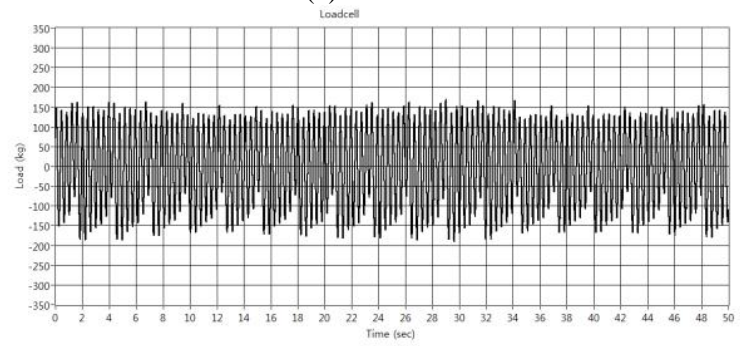

(c) Wave \#6.

Fig. 4. Measured wave force of Monopile.

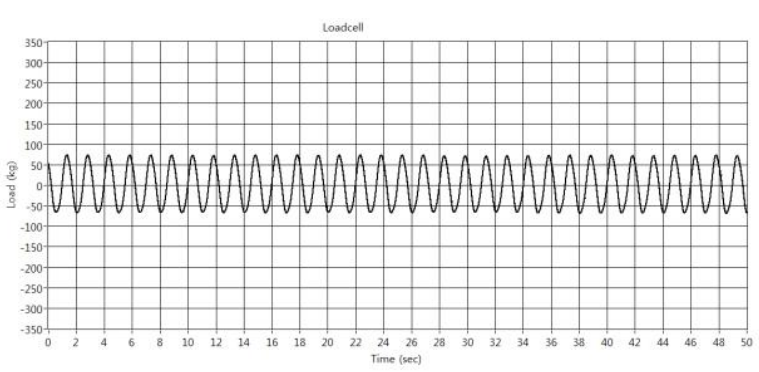

(a) Wave \#1.

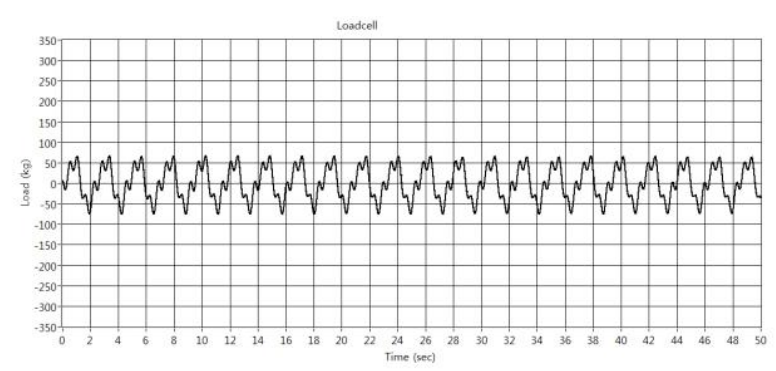

(b) Wave \#3.

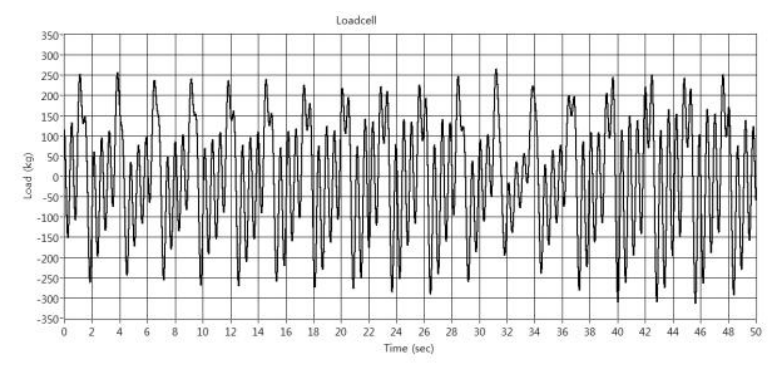

(c) Wave \#6.

Fig. 5. Measured wave force of GBS.

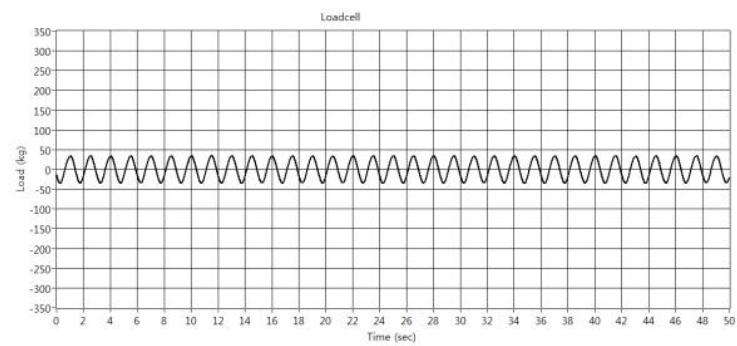

(a) Wave \#1.

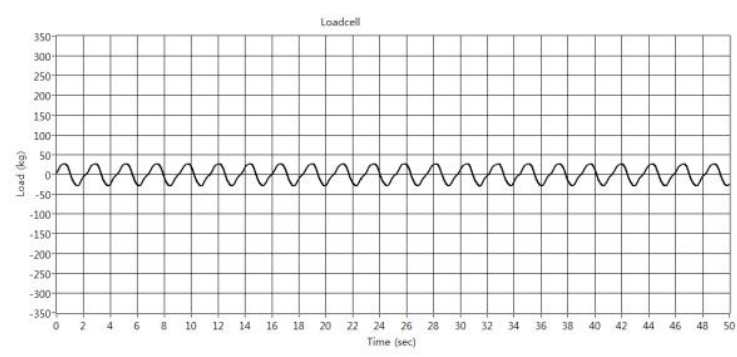

(b) Wave \#3.

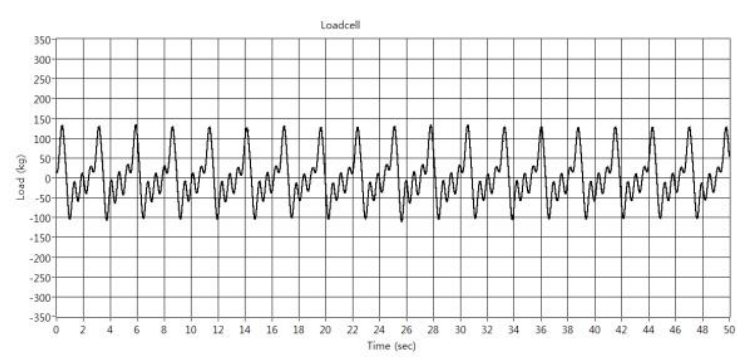

(c) Wave \#6.

Fig. 6. Measured wave force of hybrid (1): $0^{\circ}$.

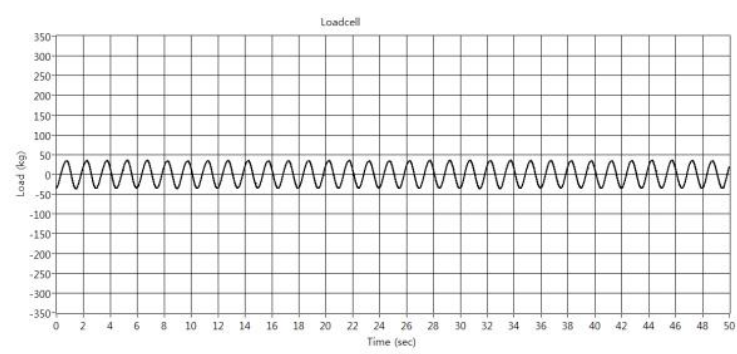

(a) Wave \#1.

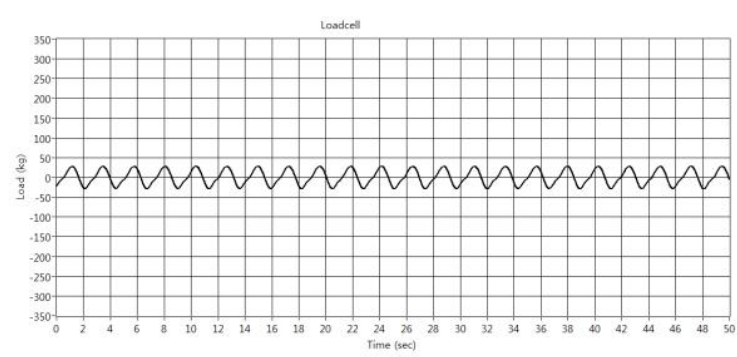

(b) Wave \#3.

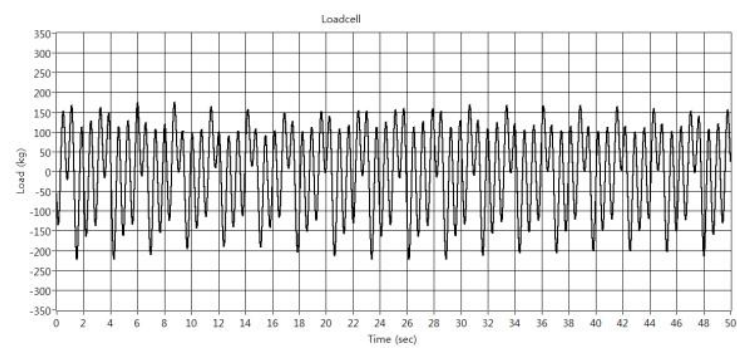

(c) Wave \#6.

Fig. 7. Measured wave force of hybrid (2): $45^{\circ}$. 


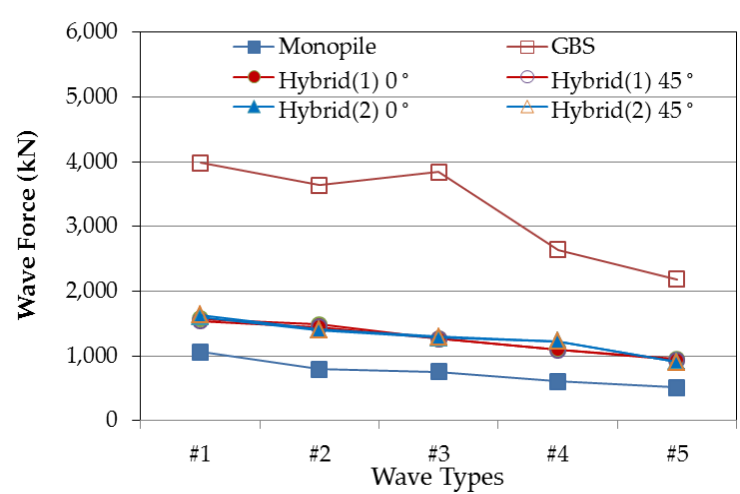

Fig. 8. Wave forces to wave periods at normal wave condition.

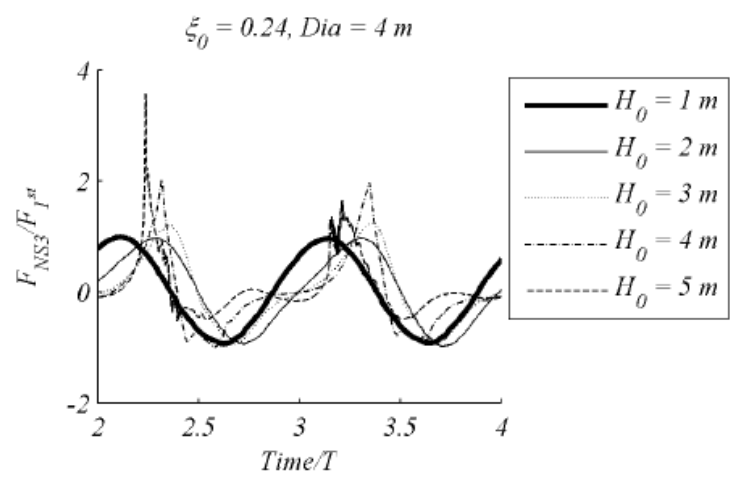

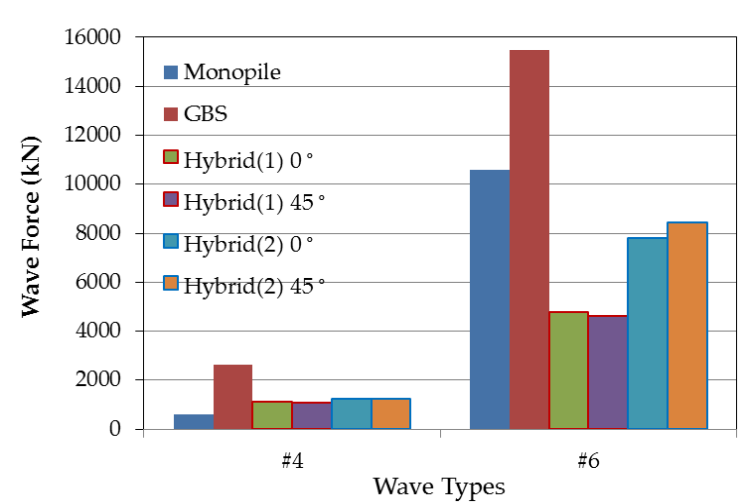

Fig. 9. Wave forces to wave heights at extreme wave condition.

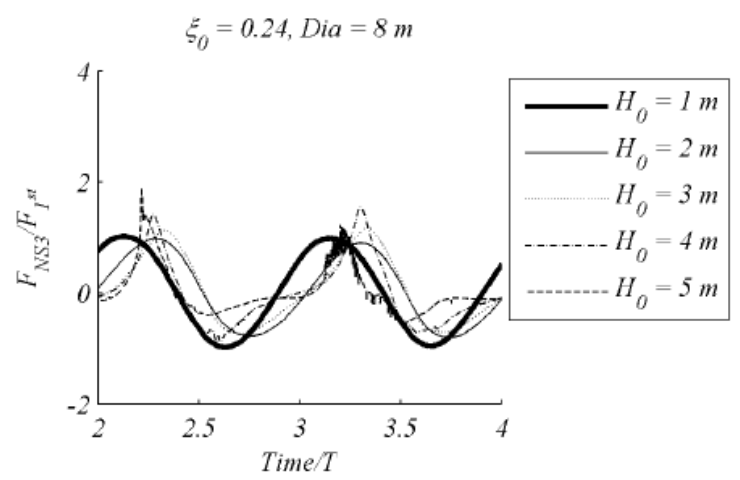

Fig. 10. Extreme wave force to the wave height and diameter of support structure [5].

TABLE IV: WAVE IMPACT FORCE FACTORS

\begin{tabular}{|c|c|c|}
\hline References & Impact factor & Type \\
\hline DNV-OS-J101 & 5.15 per unit length & \multirow{3}{*}{$\begin{array}{l}\text { Vertical } \\
\text { cylinder }\end{array}$} \\
\hline DNV-RP-C205 & 5.15 per unit length & \\
\hline API RP 2A-WSD & $0.5 \pi$ to 1.7 per unit length & \\
\hline Ros & 4.3 (test result) & Monopile \\
\hline
\end{tabular}

It was natural that impact wave force effect was insignificant for the Hybrid (1) and Hybrid (2) models since the upper part consists of slender member of the multiplies. However, it was a question that the impact wave force effect of GBS type was minute. According to the other theoretical study [6], as the diameter of the support structure increased within the certain range, it was found that impact wave force degreased in rather. Therefore, impact wave force effect of this study for the GBS type maybe in correct.

Hybrid (1) and Hybrid (2), which have the same dimension but different total weight, were indicated different levels of the wave force at the extreme wave condition of wave \#6. It was caused by different inertia force due to the wave-induced little vibration of the test models at the extreme wave condition. Therefore, it was found that the total weights of the support structures influence on the wave force subjected to the support structure at the extreme wave condition.

Wave forces of GBS type indicated the largest wave force among the four support structures, about $506 \%$ of the Monopile at the normal wave condition of wave \#3 and about $146 \%$ of the Monopile at the extreme wave condition of wave \#6. At the extreme wave condition of wave \#6, wave force of Hybrid (1) and Hybrid (2) indicated about $44.0 \%$ to $80.0 \%$ of the Monopile [3], as shown in Fig. 9, although wave force of Hybrid (1) and Hybrid (2) indicated about $181 \%$ to $203 \%$ at the normal wave condition of wave \#4.

Summarizing wave test results, as the wave period increased maintaining the same wave height at the normal wave condition, wave force subjected to the support structures decreased for the most support structures. Also, total weights of the support structures insignificantly influence on the wave force subjected to the support structure at the normal wave condition.

As the wave height increased maintaining the same wave period at the extreme wave condition, wave force subjected to the support structures influenced by impact wave force called slamming force. Wave run-up and impact wave force were mainly dependent on the shape of support structure, wave height, and wave period. Impact wave force of this study significantly effects on the Monopile and not to the other models. Total weights of the support structures influence on the wave force subjected to the support structure at the extreme wave condition, against to the normal wave condition.

In respects of the structural design, critical loading is wave force at the extreme wave condition rather than the normal wave condition. Hybrid (1) and Hybrid (2) have a larger wave projection area about $180 \%$ of the Monopile, as presented in Table I. Therefore, Hybrid (1) and Hybrid (2) indicated higher wave forces about $145 \%$ to $203 \%$ (average $174 \%$ ) of the Monopile at the normal wave condition of wave \#1 to wave \#5. However, at the extreme wave condition of wave \#6, Hybrid (1) and Hybrid (2) indicated lower wave forces about $44 \%$ to $80 \%$ (average $60.8 \%$ ) of the Monopile. It was caused by lower wave run-up and impact wave force according to the fluid-multipile interaction. The upper part of Hybrid (1) and Hybrid (2) consist of the slender multipiles which is advantages to reduce wave run-up and impact wave force at the extreme wave conditions. Therefore, it was expected that the Hybrid model of this study contribute to improve structural safety of offshore support structure as decreasing wave force at the extreme wave conditions. 


\section{CONCLUSION}

In this study, wave force tests were carried out for the four types of offshore support structures, Monopile, GBS (Gravity Base System), Hybrid (1), and Hybrid (2). Based on the wave force tests, wave forces to the shape of the support structures were analyzed and compared with each other.

As the results of this study, it was found that, as the wave period increased maintaining the same wave height at the normal wave condition, wave force subjected to the support structure decreased for the most cases. As the wave height increased maintaining the same wave period at the extreme wave condition, wave force subjected to the support structure influenced by impact wave force called slamming force. Although impact wave force of this study significantly effects on the Monopile, since the impact wave force were mainly dependent on the support structure shape, wave height, and wave period, more research is needed to access the impact wave force for other support structure shape and wave condition.

In respects of the structural design, critical loading is wave force at the extreme wave condition rather than the normal wave condition. Although Hybrid (1) and Hybrid (2) models have a larger wave projection area than the Monopile, Hybrid (1) and Hybrid (2) models indicated lower wave forces than the Monopile at the extreme wave condition resulting from lower impact wave force effects and inertia force. Therefore, it was expected that the Hybrid model of this study contribute to improve structural safety of offshore support structure as decreasing wave force at the extreme wave conditions.

\section{ACKNOWLEDGMENT}

This study was supported by the Ministry of Trade, Industry, and Energy of South Korea, Project No: 20123010020110 (Development of Hybrid Substructure System for Offshore Wind Farm), Project No: 20153030071630 (Development of 3kW cylindrical wave energy system with horizontal rotation for increasing gross generation), and by the Ministry of Oceans and Fisheries, Project No: 20120093 (Development of Concrete Substructure System and Design Guideline for Offshore Wind Farm).

\section{REFERENCES}

[1] M. S. Park, W. C. Koo, and K. Kawana, "Numerical analysis of the dynamic response of an offshore platform with a pile-soil foundation system subjected to random waves and currents," Journal of Waterway, Port, Coastal, and Ocean Engineering-ASCE, vol. 138, no. 4, pp. 275-285, 2012
[2] M. S. Park, W. C. Koo, and Y. R. Choi, "Hydrodynamic interaction with an array of porous circular cylinders," International Journal of Naval Architecture and Ocean Engineering, vol. 2, no. 3, pp.146-154, 2010.

[3] Y. J. Jeong, M. S. Park, Y. J. You, and D. H. Lee, "Shape dependent wave force and bending moment of offshore wind substructure system," Oceans2015, No. 1141201-013, Genova, Italy, 2015.

[4] L. De Vos, P. Frigaard, and J. De Rouck, "Wave run-up on cylindrical and cone shaped foundations for offshore wind turbines," Coastal Engineering, vol. 54, no. 1, pp. 17-29, 2007.

[5] M. A. Chella, A. Torum, and D. Myrhaug, "An overview of wave impact forces on offshore wind turbine substructures," Energy Procedia, vol. 20, pp. 217-226, 2012.

[6] E. D. Christensen, H. Bredmose, and E. A. Hansen, "Extreme wave forces and wave run-up on offshore wind turbine foundations," in Proc. Copenhagen Offshore Wind Conference, pp. 1-10, 2005.

[7] T. Fischer, W. De Vries, and B. Schmidt, Upwind Design Basis (WP4: Offshore Foundations and Support Structures), Upwind, 2010.

[8] W. Brook-Hart, P. A. Jakson, M. Meyts, and P. Gifford, "Competitive concrete foundations for offshore wind turbines," International Foundation, 2010.

[9] M. S. Park, Y. J. Jeong, Y. J. You, and D. H. Lee, "Numerical analysis of a gravity substructure with suction bucket foundation for $5 \mathrm{MW}$ offshore wind turbine," International Journal of Emerging Technology and Advanced Engineering, vol. 5, no. 10, pp. 59-65, 2015.

[10] Y. J. Jeong, Y. J. You, M. S. Park, D. H. Lee, and B. C. Kim, "CFMP based offshore wind substructure system and modular installation method," EWEA 2014-130505, Barcelona, Spain, 2014.

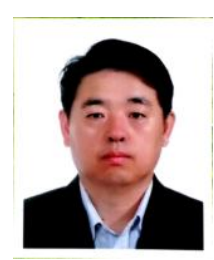

Youn-Ju Jeong earned the Ph.D. in civil engineering from Yonsei University, Seoul, Korea. He has been working for Korea Institute of Civil Engineering and Building Technology (KICT) in Gyeonggi-Do, Kore since 1994 and his current position is research fellow He participated in some projects for the offshore and marine structures. He now studies on offshore suppor1 structure.

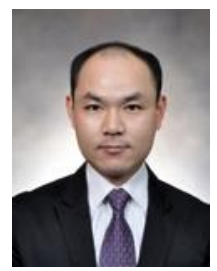

Min-Su Park earned his Ph. D. in system information engineering from Kagoshima University, Kagoshima, Japan. He has been working for Korea Institute of Civil Engineering and Building Technology (KICT) in Gyeonggi-Do, Korea since 2012 and his current position is senior researcher. He participated in some projects for the offshore structure and offshore renewable energy. He now studies on wave energy devices and substructure for offshore wind turbine.

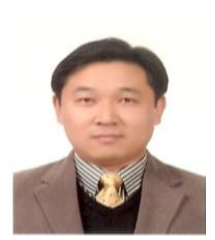

Young-Jun You earned his Ph.D. in civil engineering from Yonsei University, Seoul, Korea. He has been working for Korea Institute of Civil Engineering and Building Technology (KICT) in Gyeonggi-Do, Korea since 1998 and his current position is senior researcher. He participated in some projects for developing GFRP (Glass Fiber Reinforced Polymer) reinforcement for concrete structures and strengthening and rehabilitation of stuctures. He now studies on offshore support structures. 